\title{
Deuterium Isotope Effects and Stereochemistry in the Dealkylation and Deamination of Amphetamines and Ephedrines in Man
}

\author{
T. B. VREE, A. Th. M. J. MUSKENS and J. M. VAN ROSSUM \\ Department of Pharmacology, University of Nijmegen, \\ Nijmegen, The Netherlands
}

(Received 1 October 1971)

In man, when the urine is kept acidic, amphetamines are deaminated to an extent of $30 \%$ and excreted into the urine unchanged to an extent of $70 \%$ of the dose. With the assumption that from each amount of amphetamine, as original compound or circulating as metabolite, $70 \%$ is excreted unchanged and $30 \%$ is deaminated, the percentages of deamination, dealkylation and excretion of $\mathrm{N}$-alkyl substituted amphetamines can be measured and calculated. In the series of $N$-methyl, $N$-ethyl, and $N$-isopropyl amphetamines, the percentage of deamination remained fairly constant, but the dealkylation increased and excretion decreased. The dextro isomers showed this behaviour, but the laevo isomers did not. In this series we were dealing with a change in the mode of the $\mathbf{C}-\mathbf{H}$ binding of the alkyl group. It was supposed that the $\mathrm{C}-\mathrm{H}$ binding was involved in the rate-limiting step of the enzymic oxidative deamination and dealkylation. Therefore, the amphetamines were deuterated, and under identical circumstances the difference in metabolic behaviour of isopropyl- and deuteroisopropylamphetamine was measured. The dextro isomers showed a deuterium isotope effect, the laevo isomers did not (Vree, et al., 1971).

The mixed function oxidase, cytochrome $P-450$, showed an increased affinity for the dextro isomers, as the size of the alkyl group is increased (Schenkman, Orrhenius \& Hoffstrom, personal communication). Ephedrines show the same metabolic pathways as the amphetamines. With the amphetamines the stereochemical configuration of the tertiary $\mathrm{C}-\mathrm{H}$ binding is the key in the deamination and dealkylation (Vree, et al., 1971). When the interaction of this $\mathrm{C}-\mathrm{H}$ group with the enzyme is hindered it affects deamination and dealkylation. The hydroxyl group of the ephedrines may also hinder deamination and dealkylation. To show any difference in metabolic behaviour, the extent of metabolism to total excretion should be significant, so the $2 S$ (dextro configuration of the amphetamines) configuration was chosen. The ephedrines are less lipid-soluble than the corresponding amphetamines (Vree, Muskens \& van Rossum, 1969). The most pronounced difference in metabolic behaviour was expected for the $1 \mathrm{R}, 2 \mathrm{~S}$ and $1 \mathrm{~S}, 2 \mathrm{~S}$ isopropylnorephedrine and the results are given in the table. The results found with the $1 \mathrm{~S}, 2 \mathrm{~S}$ ephedrines are in agreement with those published by Wilkinson \& Beckett (1968). 
Differences between renal excretion, dealkylation and deamination of $1 R, 2 S$ and 1S, 2S alkylsubstituted norephedrines

\begin{tabular}{llccc}
\hline \multirow{2}{*}{ Compound } & \multicolumn{3}{c}{ (Percentage dose) } \\
\cline { 3 - 5 } & & Excretion & Dealkylation & Deamination \\
\hline \multirow{2}{*}{ 1R, 2S } & norephedrine & 75 & - & 25 \\
& methyl-norephedrine & 60 & 15 & 25 \\
& ethyl-norephedrine & 40 & 25 & 30 \\
1S, 2S & isopropyl-norephedrine & 20 & 50 & 30 \\
& norpseudoephedrine & 95 & -7 & 5 \\
& methyl-norpseudoephedrine & 85 & 15 & 8 \\
& ethyl-norpseudoephedrine & 60 & 20 & 40 \\
\hline
\end{tabular}

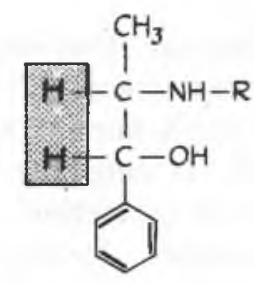

nor-ephedrine (s) erythro-1R,2S

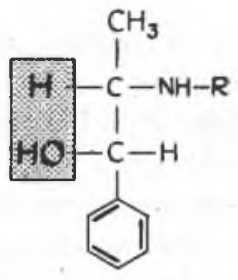

nor-ephedrine (s) threo-15,25

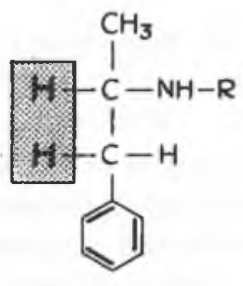

25-amphetamine (s)

$R=H$, methyl, ethyl, isopropyl

\section{References}

Vree, T. B., Gorgels, J. P. M. C., Muskens, A. Th. J. M. \& van Rosstim, J. M. (1971). Clinica chim. Acta, 34, 333.

Vree, T. B., Muskens, A. Th. J. M. \& van Rossum, J. M. (1969). Ұ. Pharm. Pharmac., 21, 774.

Wilkinson, G. R. \& Beckett, A. H. (1968). . Pharmac. exp. Ther., 162, 139. 